\title{
Evaluation of the Knowledge of CT Scan Prescribers on Patients' Radioprotection in Senegal
}

\author{
Serigne Moussa Badiane ${ }^{*}$, Pape Ibrahima Sane ${ }^{2}$, Coumba Ndoffene Ndiaye ${ }^{2}, K^{2}$ alidou Gueye ${ }^{2}$, \\ Oumar Ndoye ${ }^{2}$, Kuassi M. Amoussou-Guenou ${ }^{3}$, Mamadou Mbodji²
}

${ }^{1}$ Biophysics and Nuclear Medicine, Gaston Berger University, Saint-Louis, Senegal ${ }^{2}$ Biophysics and Nuclear Medicine, Cheikh Anta DIOP University, Dakar, Senegal

${ }^{3}$ Biophysics and Nuclear Medicine, Abomey-Clavi, Benin University, Benin

Email: *drmoussabadiane@gmail.com

How to cite this paper: Badiane, S.M., Sane, P.I., Ndiaye, C.N., Gueye, K., Ndoye, O., Amoussou-Guenou, K.M. and Mbodji, M. (2019) Evaluation of the Knowledge of CT Scan Prescribers on Patients' Radioprotection in Senegal. Open Journal of Biophysics, 9, 204-217.

https://doi.org/10.4236/ojbiphy.2019.93015

Received: April 30, 2019

Accepted: July 23, 2019

Published: July 26, 2019

Copyright (๑) 2019 by author(s) and Scientific Research Publishing Inc. This work is licensed under the Creative Commons Attribution International License (CC BY 4.0).

http://creativecommons.org/licenses/by/4.0/

\begin{abstract}
Medical imaging has enabled major improvements in the medical care of the patient. However, some of these tests have the disadvantage of using ionizing radiation at low doses. Although the CT scan is a powerful diagnostic tool, it remains a highly radiant imaging modality. In addition, the risk of radiation-induced cancer associated with low X-ray doses is established by the American Phase 2 study BEIR VII, and preventive measures require a good level of knowledge on radioprotection by imaging test prescribers. In our study, we evaluated the knowledge of CT scan prescribers in Senegal regarding patient radioprotection. These prescribers consisted of physicians and surgeons without distinction of specialty. Our objective was to have the required data for optimizing CT prescriptions in compliance with the principles of radioprotection. Our work focused on a descriptive analytical study of 107 doctors who prescribed CT scan in public health institutions in Senegal. Our results revealed poor knowledge of doctors prescribing CT scan on induced radio risks, even though the majority of them stated that they took those risks into account. Our data were not isolated, they were applicable to similar studies conducted outside Senegal. In summary, our study led on the one hand to recommendations on initial and continuing training and on the other hand on organizational and regulatory considerations.
\end{abstract}

\section{Keywords}

Radioprotection, Risk of Radiation-Induced Cancer, CT Scan Prescribers, Health Institutions in Senegal 


\section{Introduction}

The medical use of ionizing radiation has become the most important source of irradiation in the world. On the one hand, the knowledge and skills of professionals using this radiation determine the implementation of radioprotection measures recommended by international and national organizations. On the other hand, the situation in African countries is worrying due to the absence and/or non-compliance with radioprotection laws and regulations. In Senegal, CT scanning equipment is on the rise and CT scans are regularly prescribed in hospitals. Although the CT scan is a powerful diagnostic tool, it remains a highly radiant imaging modality. In addition, the risk of radiation-induced cancer associated with low X-ray doses is established by the American Phase 2 study BEIR VII [1]. However, compliance with the principles of justification, optimization and limitation requires a good level of knowledge by prescribers regarding patient radioprotection. We evaluated the knowledge of CT scan prescribers in Senegal following the model of the study by Gervaise et al. [2] conducted in 2011 in France to assess the level of knowledge of CT scan prescribers about patient radioprotection. Our objective is to have sufficient data to optimize CT prescriptions in compliance with the principles of radioprotection. Our study involved 107 doctors, including senior and junior doctors.

\section{Materials and Methods}

The study involved prescribers from 10 hospitals in Senegal.

This was a descriptive and analytical cross-sectional study of 107 doctors, including senior and junior doctors (trainees and junior registrars who prescribe CT scan.

- Criteriaof inclusion

All the doctors prescribing CT scan and who agreed to answer to the questions were included.

- Criteria of non-inclusion

All medical imaging specialists and CT scan practitioners even if they are also prescribers.

- Data collection

The data were collected using a questionnaire (see Appendix).

The questionnaire was submitted to the prescribers and then retrieved after a minimum period of 24 hours. The data were collected by second-year-medical students further to their course on radioprotection.

The data collected were verified, recorded and analyzed using Excel software.

- Data collected

The data collected concerned mainly the following parameters:

The status of senior or junior doctors.

Their unit.

The management of the benefit-risk ratio when prescribing a CT scan.

The level of irradiation during a CT scan. 
The risk of radiation-induced cancer.

Whether or not they have received training on radioprotection.

Whether or not they have read a handbook on the proper use of imaging tests at least once (See the survey sheet).

- Ethical consideration

The free and informed consent of the interviewees was obtained in advance and confidentiality was guaranteed.

\section{Results}

107 Questionnaires were submitted to the doctors and among them 102 responded (Table 1). This distribution corresponds to $49 \%$ of doctors in training and $51 \%$ of senior doctors (Diagram 1).

Question 1. Do you prescribe CT scan?

To this question, $96 \%$ of juniors and $94.4 \%$ of respondents said they prescribe CT scan (Table 2).

Question 2. When prescribing a CT scan, have you ever considered the benefit/risk ratio of X-rays?

In this question, $57 \%$ of the prescribers affirmed to take into account the benefit-risk ratio against $43 \%$ (Table 3 and Diagram 2).

Among those who take into account the benefit-risk ratio $60 \%$ are seniors compared to $40 \%$ of juniors (Figure 1 ).

Question 3. When prescribing a CT scan, have you already informed the patient about the risks associated with $\mathrm{x}$-rays and the resulting benefit/risk ratio features?

Table 1. Number of questionnaires submitted to doctors.

Number of questionnaires submitted to doctors: 107 (see diagram number 1)

Number of questionnaires treated $=102$

Number of unanswered questionnaires $=05$

Status

Junior doctors

Seniors

Total

50

52

Table 2. Frequency of prescription of CT scan.

\begin{tabular}{ccccc}
\hline Status & \multicolumn{2}{c}{ Junior doctors } & \multicolumn{2}{c}{ seniors } \\
\hline Answers & yes & no & yes & no \\
\hline Total & 50 & 2 & 52 & 3 \\
Percentage of prescribers & & $96 \%$ & & \\
\hline
\end{tabular}

Table 3. Benefit-risk consideration.

\begin{tabular}{ccccc}
\hline Status & \multicolumn{2}{c}{ Junior doctors } & \multicolumn{2}{c}{ seniors } \\
\hline Answers & yes & no & yes & no \\
Total & 23 & 27 & 35 & 17 \\
\hline
\end{tabular}




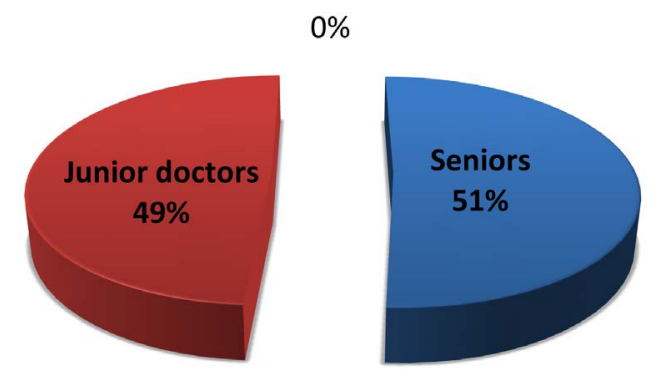

Diagram 1. Distribution of prescribers by status.

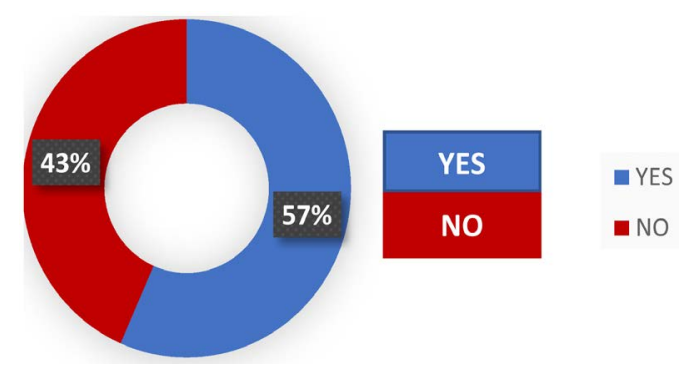

Diagram 2. frequency of prescribers that take into account the benefit/risk ratio.

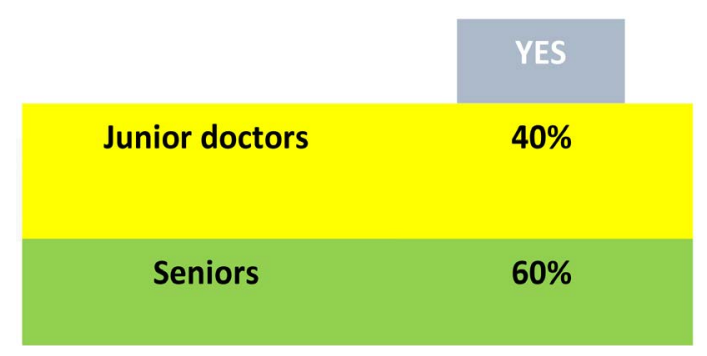

Figure 1. Statutes of the prescribers considering the benefit/risk ratio.

In this question, $25 \%$ of the prescribers affirmed informing their patients of the benefit-risk ratio against 75\% (Table 4 and Diagram 3).

Among those who claim to inform their patients, there were $44 \%$ of junior prescribers and $56 \%$ of senior (Figure 2).

Question 4. In your opinion, and compared to the dose delivered for a chest X-ray (RT), the average dose delivered during a standard abdominal CT scan is equivalent to:

$0.5 \%$ of participants gave the right answer (Table 5 and Diagram 4 ).

Expected correct response: Compared to the dose delivered for chest X-ray (RT), the average dose delivered during a standard abdominal CT scan is equivalent to $100 \mathrm{RT}<\mathrm{CT}<250 \mathrm{RT}$.

Question 5. Knowing that the natural irradiation is about $2.5 \mathrm{msv} / \mathrm{year}$, how much do you estimate the average dose delivered during an abdominopelvic CT scan?

$0.4 \%$ of participants gave the right answer. 
Table 4. Patient information on the benefit-risk ratio.

\begin{tabular}{ccccc}
\hline Status & \multicolumn{2}{c}{ Junior doctors } & \multicolumn{2}{c}{ seniors } \\
\hline Answers & yes & no & yes & no \\
\hline Total & 11 & 39 & 14 & 38
\end{tabular}

Table 5. Knowledge of the radiation dose level of an abdominopelvic CT compared to a chest X-ray.

\begin{tabular}{ccccccc}
\hline Characteristics & $\mathrm{CT}<\mathrm{RT}$ & $\begin{array}{c}\mathrm{RT}<\mathrm{CT}< \\
10 \mathrm{RT}\end{array}$ & $\begin{array}{c}10 \mathrm{RT}<\mathrm{CT}< \\
100 \mathrm{RT}\end{array}$ & $\begin{array}{c}100 \mathrm{RT}<\mathrm{CT}< \\
250 \mathrm{RT}\end{array}$ & $\begin{array}{c}250 \mathrm{RT}< \\
\mathrm{CT}\end{array}$ & $\begin{array}{c}\text { Do not } \\
\text { know }\end{array}$ \\
\hline Answers & 26 & 24 & 11 & 5 & 3 & 33 \\
\hline & & & & & & \\
& & &
\end{tabular}

Diagram 3. Frequency of prescribers who inform their patients about the benefit/risk ratio.

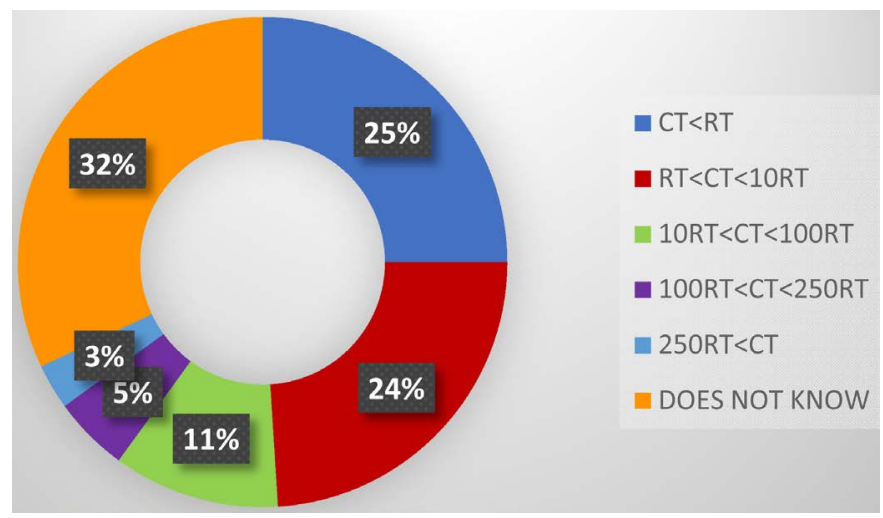

Diagram 4. Frequency of prescribers who know the radiation dose level of an abdominopelvic CT compared to a chest X-ray.

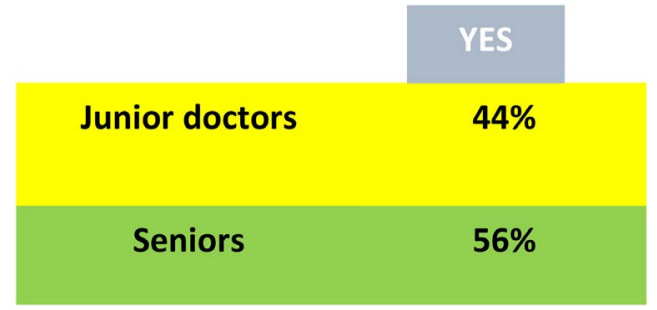

Figure 2. Statutes of the prescribers informing about the benefit/risk ratio. 
Expected correct response: The average dose delivered during an abdominal pelvic CT scan is estimated between 5 to $20 \mathrm{mSv}$ (Table 6 and Diagram 5).

Question 6. According to the latest consensus conferences, there is a risk of developing radiation-induced cancer due to the dose delivered during a single standard abdominal-pelvic CT scan. If yes, how high do you estimate this risk?

$17 \%$ of the participants gave the right answer.

Expected correct answer: A risk of developing radiation-induced cancer due to the dose delivered during a single standard abdominal-pelvic CT scan is estimated at 1/1000 (Table 7 and Diagram 6).

Table 6. Comparison of natural irradiation versus an abdominopelvic CT scan.

\begin{tabular}{ccccc}
\hline Characteristics & $<5 \mathrm{mSv}$ & 5 to $20 \mathrm{mSv}$ & $<20 \mathrm{mSv}$ & Do not know \\
\hline Answers & 19 & 4 & 16 & 63 \\
\hline
\end{tabular}

Table 7. Risk of radio cancer induced at low doses.

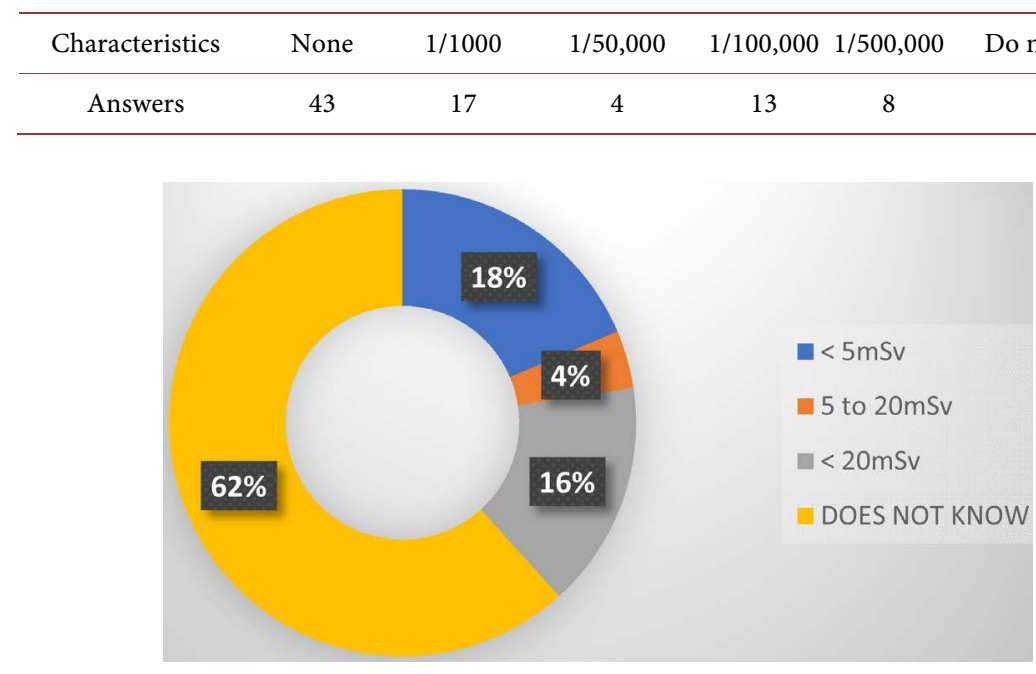

Diagram 5. Frequency of prescribers who know the radiation dose level of an abdominopelvic CT compared to natural irradiation.

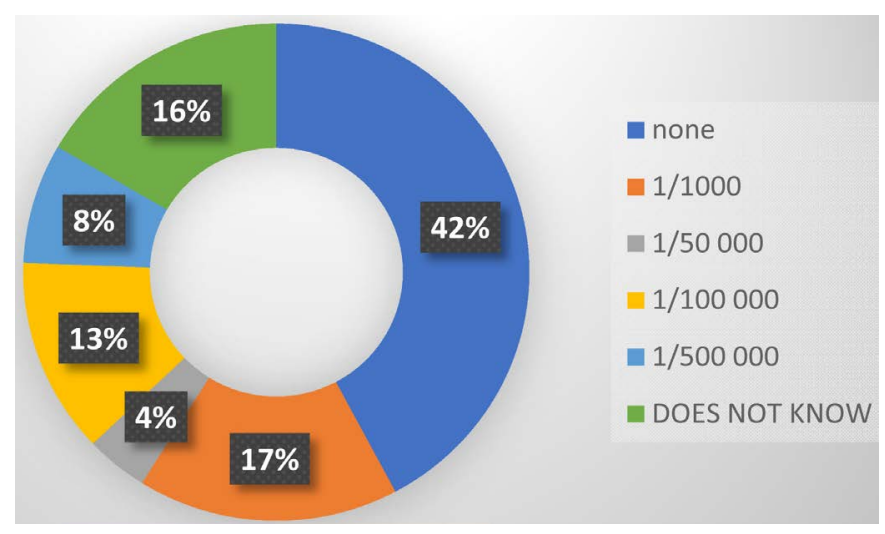

Diagram 6. Frequency of prescribers who know the level of risk of radiation-induced cancer based on the latest consensus conferences. 
Question 7. Have you ever been trained on patient radioprotection?

$9 \%$ of prescribers claim to have received radiation protection training (Table 8 and Diagram 7). The proportion of prescribers claiming to have been trained is $55.6 \%$ for junior versus $44.4 \%$ for seniors (Figure 3 ).

Question 8. Have you ever read a handbook on the proper use of medical imaging tests?

To this question, $23 \%$ of prescribers stated that they had already consulted a guide (see Table 9, Diagram 8 ). Of those, $43.5 \%$ were junior and $56.5 \%$ were

Table 8. Radiation protection training.

\begin{tabular}{cccccc}
\hline Characteristics & \multicolumn{2}{c}{ Junior doctors } & \multicolumn{2}{c}{ Seniors } \\
\hline Answers & yes & no & yes & no \\
\hline Staff & 5 & 45 & 4 & 48
\end{tabular}

Table 9. Prescribers claiming to have already consulted a guide to the correct use of médical imaging exams.

\begin{tabular}{ccccc}
\hline Characteristics & \multicolumn{2}{c}{ Junior doctors } & \multicolumn{2}{c}{ Seniors } \\
\hline Answers & yes & no & yes & no \\
\hline Staff & 10 & 40 & 13 & 39 \\
\hline
\end{tabular}

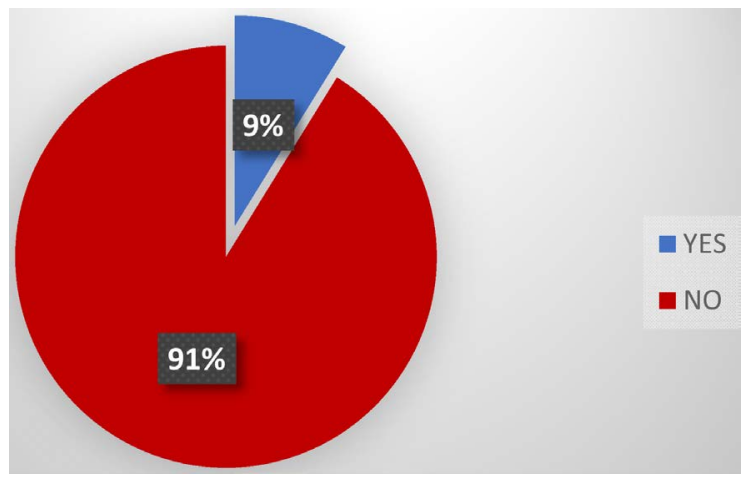

Diagram 7. Frequency of prescribers who have received radiation protection training.

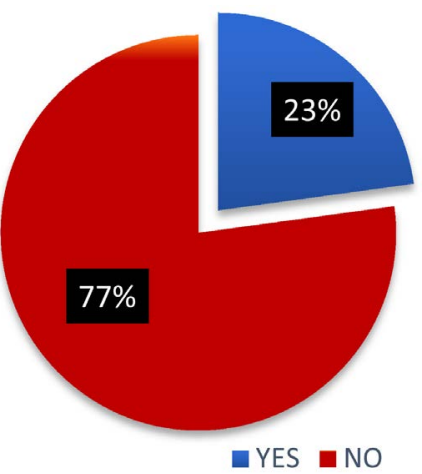

Diagram 8. Frequency of prescribers who have already consulted a guide to the correct use of imaging screens. 


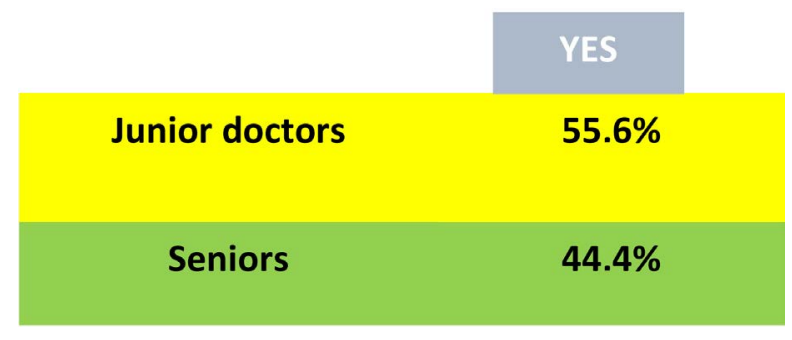

Figure 3. Statutes of prescribers informing about the benefit/risk ratio.

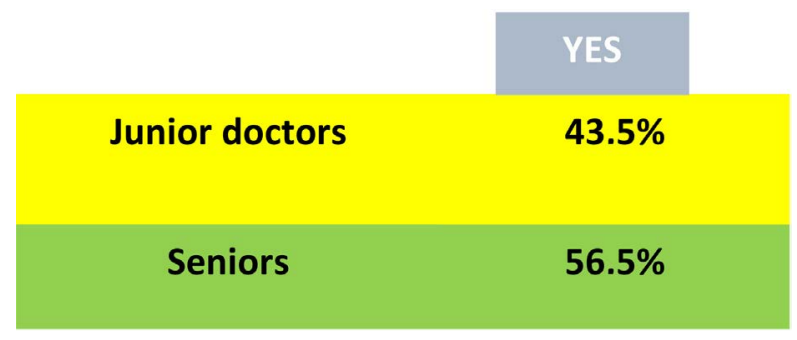

Figure 4. Statutes of the prescribers claiming to have already consulted a guide of good use in imagery.

seniors (Figure 4).

\section{Discussion}

\subsection{Analytical Interpretation of the Survey Results}

Medical science uses various sources of ionizing radiation, produced either by electric generators or by radionuclides. While their medical interest and usefulness have been established, these techniques contribute significantly to the population's exposure to ionizing radiation. After natural exposure, they represent the second most important source of exposure for the population and the first source of artificial origin. The current state of knowledge on the dangers and risks associated with ionizing radiation has led the international community to set health objectives for radioprotection aiming at avoiding the appearance of so-called tissue or deterministic reactions but also at reducing the probability of radiation-induced cancers [3]. The interest of knowing the risk of radiation-induced cancer is an element of radioprotection.

To this end, studies focusing on good imaging practices and compliance with handbooks for the prescription of irradiating imaging tests are arousing growing interest within the scientific community. The choice amongst imaging modalities is therefore in favour of non-irradiating techniques and, failing that, the lowest doses possible.

Our study shows that prescribers' knowledge on patient radioprotection is unsatisfactory, with a significant underestimation of the level of radiation doses delivered to patients and the potential risks of radiation-induced cancer that result from them. However, this observation is not only limited to the prescribing doctors in our study, but is consistent with the results of numerous studies con- 
ducted on populations of hospital practitioners [2] [4] and also on a population of radiologists, although to a lesser extent [5].

For example, for Lee et al. in a study conducted in 2004 [6], only $9 \%$ of paramedics reported that they thought there was an increased risk of radiation-induced cancer due to the use of a CT while only $22 \%$ of them had informed the patient. The dose ratio between a CT scan and a frontal chest X-ray was also significantly underestimated.

In another similar study, conducted in 2004 [7] Jacob et al. found a higher correct response rate among the group of doctors who had previously received patient radioprotection training compared to the group who had never received such training.

The course on radioprotection in the medical program is only delivered during the first cycle of medical study without any particular focus, thus at the end of the training curriculum the doctor keeps only vague memories of the concepts of radioprotection. Furthermore, the availability and distribution of prescription handbooks for imaging tests is an issue.

Therefore, the training of practitioners on radioprotection seems to play a key role. However, although the interest of such training is highlighted by organizations such as Euratom, [4] it seems to be neglected in medical programs. Such training would allow a better knowledge and consideration of the potential risk of radiation-induced cancer associated with low $\mathrm{X}$-ray doses by prescribers. This could then lead to a better justification for irradiating imaging tests and also help the patient get the right information.

Moreover, with the current availability of publications, the patient can already find a lot of information on the Internet or in the newspapers that the prescriber must be able to comment on and sometimes qualify. However, in some circumstances, this information which the doctor should provide to the patient becomes a must. This is particularly the case for pregnant women or young patients with chronic pathologies requiring repeated CT scan.

The limited knowledge of prescribing doctors about patient radioprotection challenges the "quality" of their medical care. Quality in the provision of medical care takes into account the availability of protocols, information for practitioners and patients [6]. Improving the quality of medical care in our contexts of operation will require CT prescribers to be aware of the concepts of radioprotection, justification, optimization and limitation of the risk of radiation exposure.

We have found that prescribing doctors do not feel comfortable with radioprotection and are not involved in this practice. Krille et al. [8] in their 2010 literature review assessed doctors' knowledge of the doses and risk of CT scan. Thus, despite the methodological differences of the 14 studies included, this article concludes that doctors' risk awareness should increase. This lack of professional involvement is more prevalent in the medical field than in other fields using ionizing radiation [9]. In the February 2008 publication of the journal "Bulletin and Memoirs of the Belgian Royal Academy of Medicine", Dr. Smeesters compares the radiological risk awareness and radioprotection knowledge of 
medical staff (diagnostic and therapeutic) with the knowledge of professionals using ionizing radiation in an industrial setting. According to the author, radioprotection culture and risk awareness are less widespread in the medical field than in other sectors using ionizing radiation [10]. The first concern of doctors is to establish a diagnosis and treat effectively, so radioprotection logically takes a back seat [4]. This attitude would not be related to negligence or opposition to radioprotection strategies, but rather to ignorance. They are also unanimous in recognizing a risk to the repeated use of ionizing tests, even if this assessment is uncertain and presents a strong inter-individual variability. However, an article in the Swiss Doctors' newsletter reports that doctors feel uncomfortable when informing patients about the radiological risk [10].

\subsection{Statistical Approach}

We chose a descriptive approach to provide a detailed picture of the knowledge of CT prescribers about patient radioprotection.

Two variables should be noted:

- an independent variable that is the status of prescribing doctors.

- a dependent variable which is the level of knowledge about patient radioprotection.

In our sampling, we had sought an approach that was fairly representative of the population of CT prescribers in Senegal.

This sample was non-probabilistic because we did not find it relevant to submit our questionnaire to radiology or nuclear medicine practitioners who are also potential prescribers.

Following our network, we have been able to move widely from University Hospital Centers to Regional Hospital Centers. This has resulted in a fairly representative sample of CT scan prescribers in Senegal. The small sample size of 107 participants is a potential source of sampling bias. Nevertheless, data saturation was achieved on a sample of maximum variables that seems to have been well conducted because if we look at the sociological characteristics of the doctors in the study, we have 52 senior doctors and 50 junior doctors. Demographically, the majority of the study is made up of urban doctors. However, despite practice and culture that may differ, the initial medical training is the same. Data collection was done using a questionnaire based on the Gervais et al. [2] model. In order to encourage the participant in the study, we avoided submitting a questionnaire that at first glance could appear complex and interfere with the desire to answer. Therefore, the first questions were accessible and we also guaranteed the anonymity of the participants and any other identification data. Our approach was cost-effective because out of 107 questions submitted, 105 doctors answered.

Depending on the participant's availability, almost all of them gave us a time slot to answer our questionnaire, while others gave us an appointment the next day to retrieve the completed questionnaires. 


\subsection{Strengths and Weaknesses}

The qualitative nature of this study reflects both the conscious opinion of prescribing doctors on radioprotection and its unconscious representation, compared to a quantitative study. Qualitative studies go beyond rationality and open up a window on what the subject "really" thinks. This allows us to see the different positions that prescribing doctors may have on the subject. The number of interviews conducted resulted in the collection of a significant amount of ideas.

For reasons of convenience and adherence, the majority of interviews were conducted at the interviewee's worksite. During the interviews, doctors were sometimes interrupted in their reasoning by the telephone or patients knocking on the door. Several interviews were conducted at the end of the day.

\subsection{Challenges of the Study}

We did not encounter any major difficulties in carrying out this work, except for the risks associated with travel.

\subsection{Major Orientations}

The purpose of studies such as ours is to improve the control of ionizing radiation risk in the sectors concerned (radiology, nuclear medicine, radiotherapy, dental surgery) and to improve the safety of patients subjected to diagnostic or curative radiation, by prioritizing the dissemination and application of the regulatory framework and its translation into national institutional and professional procedures and recommendations.

This is based on several axes, including raising awareness among all the professionals concerned (radiologists and prescribers, radio-pharmacists, medical physicists, handlers, dental surgeons) on the need to take radioprotection into account for any prescription and/or use of ionizing radiation, particularly around the principles of justification and optimization of the various modalities. But also the facilitation of the adherence and appropriation of professionals to the approaches for the analysis of practices, as proposed by the High Authority for Health in France (HAS), as a lever for the quality and safety of care [7] by involving them widely in the implementation of radioprotection procedures and measures.

However, these steps require the implementation of practical orientation training during initial and continuing medical training.

Education and training on radioprotection require strong action in some countries by the Ministry of Higher Education and Health to ensure that medical education programs better integrate the physical and biological bases of the effects of ionizing radiation, their various applications and radioprotection.

The relevant training topics would be structured around:

- the national and international regulatory legislative and institutional framework, 
- staff and patient safety requirements,

- quality control of equipment,

- employers' obligations regarding workplace safety standards, monitoring and follow-up of staff.

These steps should lead to the design of information systems on patients' doses of exposure under the supervision of the various actors and bodies concerned and the improvement of mandatory quality control for new and existing installations through measures informing about the quantity of radiation emitted during irradiation examination procedures.

In addition, it would be useful in our conditions to set up an information and advice system for doctors and patients confronted with a problem of exposure to ionizing radiation to verify the relevance of radiological examinations requested either at the level of insurance providers or even public authorities and this should be mandatory for the radiology department through a systematic welcoming of the patient by the radiologist before any imaging test. In our opinion, the radiologist should not just consider the patient and their pathology as an image to read. This robotic method of management is a strainer that reduces the chances of the patient and the quality of their medical care.

In the same line, we encourage the promotion of national expertise in radioprotection by setting up a powerful, transparent and pluralist scientific monitoring system to follow-up the evolution and critical analysis of new scientific data likely to have an impact on radioprotection in the short and long terms. The major orientation would be a vigilant and responsible radioprotection with an emphasis on the reduction of doses received by the public, patients and professionals.

These proposals comply with the report of the commission headed by Professor Constantin VROUSOS submitted to the Director General of Nuclear Safety and Radioprotection in France on $2^{\text {nd }}$ March 2004 [11].

\section{Conclusion}

The observation of low level of knowledge of CT prescribers in patient radiation protection challenges the public health authorities and learned societies on the need to train health professionals. The current upgrading of the imaging technical platforms of the main national hospitals as well as regional hospitals is turning training needs into a real emergency. The lack of continuous training of medical staff and patients on radioprotection is a disadvantage and a potentially serious risk due to the diverse profile of the staff and equipment installed in health services. In summary, our work resulted in recommendations focused on initial and ongoing training to be developed, as well as organizational and regulatory aspects to be improved.

\section{Conflicts of Interest}

The authors declare no conflicts of interest regarding the publication of this paper. 


\section{References}

[1] National Research Council, et al. (2006) Health Risks from Exposure to Low Levels of Ionizing Radiation: BEIR VII Phase 2. National Academies Press, Washington DC.

[2] Gervaise, A., Esperabe-Vignau, F., Pernin, M., et al. (2011) Evaluation des connaissances des prescripteurs de scanner en matière de radioprotection des patients. Journal de Radiologie, 92, 681-687. https://doi.org/10.1016/j.jradio.2011.03.023

[3] (2000) Sfrnet.org en ligne paris France. Société Française de Radiologie. http://www.sfrnet.org/sfr/professionnels/5-referentiels-bonnes-pratiques/directive-e uratom/index.phtml

[4] has-sante.fr en ligne Paris (France) (2012) Haute autorité de santé. https://www.has-sante.fr/portail/upload/docs/application/pdf/2013-07/radioprotecti on du patient et analyse des pratiques dpc et certification des etablissements de sante format2clics.pdf

[5] Azria, E., Bétrémieux, P., Caeymaex, L., et al. (2007) L'information dans le contexte du soin périnatal: Aspects éthiques. Archives de Pédiatrie, 14, 1231-1239. https://doi.org/10.1016/j.arcped.2007.07.005

[6] Krille, L., Hammer, G.P., Merzenich, H. and Zeeb, H. (2010) Systematic Review on Physician's Knowledge about Radiation Doses and Radiation Risks of Computed Tomography. European Journal of Radiology, 76, 36-41. https://doi.org/10.1016/j.ejrad.2010.08.025

[7] Wong, C.S., et al. (2012) A Questionnaire Study Assessing Local Physicians, Radiologists and Interns' Knowledge and Practice Pertaining to Radiation Exposure Related to Radiological Imaging. European Journal of Radiology, 81, 264-268. https://doi.org/10.1016/j.ejrad.2011.02.022

[8] Lefebvre, G., Smeesters, P. and Van Bladel, L. (2006) Contrôle et évaluation de la radioprotection des patients en Belgique: Organisation, bilan et perspectives. Contrôle, 172, 12-16.

[9] asn.fr en ligne Paris (France): Autorité de Sureté Nucléaire 2016. https://www.asn.fr/Informer/Publications/Rapports-de-l-ASN

[10] Smeesters, P., Firket, H., Smeesters, P., Frühling, J., Smeesters, P., Behar, A., Vanderhaeghen, J.-J., et al. (2008) Radioprotection et pratique médicale: Progrès, défis et menaces. Bulletin et mémoires de P Académie Royale de Médecine de Belgique, $163,145-160$.

[11] la documentationfrancaise.fr. Rapport de la commission VROUSOS. Priorites en radioprotection en ligne Paris (France): La Documentation française 2004. https://www.ladocumentationfrancaise.fr/var/storage/rapports-publics/044000102.p df 


\section{Appendix}

\section{Survey sheet.}

Evaluation of the knowledge of CT scan prescribers on patient radioprotection in Senegal

\section{QUESTIONNAIRE}

(Tick the answers that you think are correct)

Junior doctor/Senior (years of experience since the MD)........ Years

Unit:

Hospital:

Do you prescribe CT scan? (Even occasionally) Yes $\square \quad$ No $\square$

Which organ CT scan do you prescribe the most?.

When prescribing an CT scan, have you ever taken into account the benefit/risk ratio related to $x$-rays? Yes $\square$ No $\square$

When prescribing a CT scan, have you already informed the patient about the risks associated with $x$-rays and the resulting benefit/ risk ratio? Yes $\square \quad$ No $\square$

In your opinion, compared to the dose delivered for a chest X-ray (RT), the average dose delivered during an abdominal pelvic is equivalent to:

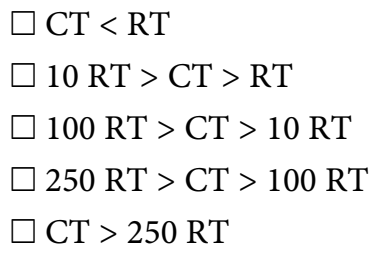

Knowing that the natural irradiation is about $2.5 \mathrm{mSv}$ per year, how much do you estimate the average dose delivered during an abdominal pelvic CT scan? $\mathrm{mSv}$

In your opinion and according to the latest consensus conferences, is there a risk of developing radiation-induced cancer due to the dose delivered during a single standard abdominal CT scan and if so, how high do you estimate this risk?

$\square$ None (= no risk of radiation-induced cancer for a single abdominal-pelvic CTscan)

$\square 1$ per 1000 (= 1 in 1000 patients at risk of developing cancer due to the dose received by having a single abdominal and pelvic CT scan)

$\square 1$ per 50,000

$\square 1$ per 100,000

$\square 1$ per 500,000

Have you ever been trained on patient radioprotection? Yes $\square \quad$ No $\square$

Have you once read a handbook on the proper use of medical imaging tests? Yes $\square \quad$ No $\square$

NB-Junior doctor $=$ specialization in progress 